\title{
Current surgical therapy for Ebstein anomaly in neonates
}

\author{
Brian L. Reemtsen, MD, Brian T. Fagan, MD, Winfield J. Wells, MD, and Vaughn A. Starnes, MD
}

Earn CME credits at http://cme.
From Children's Hospital Los Angeles and the Keck School of Medicine, Los Angeles, Calif.

Read at the Eighty-sixth Annual Meeting of The American Association for Thoracic Surgery, Philadelphia, Pa, April 29-May 3, 2006.

Received for publication April 26, 2006; revisions received July 19, 2006; accepted for publication Aug 11, 2006.

Address for reprints: Brian Reemtsen, MD, Department of Cardiothoracic Surgery, Children's Hospital of Los Angeles, 4650 Sunset Blvd, Los Angeles, CA 90027 (E-mail: brianreemtsen@yahoo.com).

J Thorac Cardiovasc Surg 2006;132:1285-90 $0022-5223 / \$ 32.00$

Copyright (C) 2006 by The American Association for Thoracic Surgery

doi:10.1016/j.jtcvs.2006.08.044
Objective: Neonates with profound heart failure resulting from Ebstein anomaly have historically had poor outcomes. We report our institutional experience with the surgical management of Ebstein anomaly in severely symptomatic neonates.

Methods: A retrospective review of all patients $(\mathrm{n}=16)$ undergoing neonatal intervention for Ebstein anomaly between 1992 and 2005 has been carried out. The indications for operation were overt heart failure, cyanosis, and acidosis associated with tricuspid regurgitation, depressed right ventricular function, and severe cardiomegaly. The magnitude of cardiac enlargement was assessed by cardiothoracic ratio and Great Ormond Street ratio (area of right atrium + atrialized right ventricle/area of functional left atrium + left ventricle). The operative strategy was first to assess for the possibility of tricuspid valve repair with or without right ventricular outflow tract reconstruction. If this was not feasible, then right ventricular exclusion was performed by oversewing the tricuspid valve with a pericardial patch. A reduction atrioplasty was done and, depending on the extent of the atrialized portion of the right ventricle, plication was performed. A modified Blalock-Taussig shunt provided pulmonary blood flow. This univentricular approach (Starnes procedure) evolved to include a fenestration in the tricuspid valve patch to allow for right ventricular decompression. Analysis included overall and group-specific survival as well as the testing of perioperative clinical, morphologic, and surgical variables for correlation with mortality and morbidity.

Results: Mean age and weight at operation were $8 \pm 10$ days and $3.1 \pm 0.4 \mathrm{~kg}$. Tricuspid valve repair was undertaken in 3 patients with 1 requiring conversion to right ventricular exclusion 3 months after the initial operation. In those with right ventricular exclusion, the tricuspid valve patch was fenestrated in 10 and nonfenestrated in 3 . One patient had heart transplant as the initial procedure. There were 5 hospital deaths (31\%) and no late deaths among the survivors. Survival in the cohort with a fenestrated tricuspid valve patch was $80 \%(8 / 10)$ versus $33 \%(1 / 3)$ for the nonfenestrated group. This difference did not reach statistical significance, although the trend seems clinically important. There was no difference in the cardiothoracic ratio ( 0.82 fenestrated vs 0.84 nonfenestrated: $P=.802)$ or the Great Ormond Street ratio (1.2 fenestrated vs 1.02 nonfenestrated: $P=.477$ ) between the two groups. Among the 9 survivors of right ventricular exclusion, 3 have had completion of their Fontan, and all 9 have undergone a bidirectional Glenn procedure. All operations including homograft placement in the right ventricular outflow tract, whether during repair or during right ventricular exclusion, ended in death.

Conclusion: Right ventricular exclusion with a fenestrated tricuspid valve patch combined with right atrioplasty and right ventriculoplasty and a Blalock-Taussig shunt (Starnes procedure) has provided effective palliation for neonates presenting with critical Ebstein anomaly and a tricuspid valve that cannot be repaired.

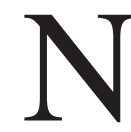
eonates with symptomatic Ebstein anomaly continue to be a difficult management problem. The disease process is much different from that of children or adults who present later in life with progressive tricuspid regurgitation and arrhythmias. Neonates can have a rapidly deteriorating course 


\section{Abbreviations and Acronyms \\ PA = pulmonary artery \\ $\mathrm{RV} \quad=$ right ventricle(ular) \\ RVOT $=$ right ventricular outflow tract}

with severe heart failure, cyanosis, and acidosis. Without surgical intervention most will die. This subgroup has historically had dismal outcomes with medical therapy, and until recently surgical intervention had little more to offer, with tricuspid valve repair or replacement associated with high mortality. ${ }^{1-3}$ Because of this, a right ventricular (RV) exclusion approach was developed and first reported by Starnes and associates ${ }^{4}$ in 1991 . This procedure included patching of the tricuspid valve and a modified BlalockTaussig shunt. Since the first reported series of RV exclusion, 16 additional neonates with extreme Ebstein anomaly have undergone palliation at our institution. This report reviews the evolution of our surgical management of these neonates and includes their intermediate-term outcomes.

\section{Patients and Methods}

A retrospective review of 16 consecutive neonates with critical Ebstein anomaly presenting between 1992 and 2005 has been carried out. Institutional approval was obtained before the inception of the study.

\section{Demographics and Preoperative Status}

The patients presented in the first days of life with severe cardiomegaly and heart failure. There were 9 girls and 7 boys with a mean weight of $3.12 \pm 0.47 \mathrm{~kg}$. Two neonates were premature (estimated 33 weeks of gestation). Six patients had a prenatal diagnosis by fetal echocardiography. In the remainder, the diagnosis was made after discovery of a murmur $(n=2)$ or cyanosis $(n=8)$. There were associated cardiac findings in most patients, including patent ductus arteriosus $(n=11)$, atrial septal defect $(n=12)$, and pulmonary valve stenosis or atresia $(n=8)$.

All 16 neonates were intubated and supported with a ventilator before repair. Fourteen (88\%) required prostaglandin E to ensure ductal patency, and $9(56 \%)$ required inotropes (dopamine, dobutamine, or epinephrine).

\section{Preoperative Assessment}

The cardiothoracic ratio was measured from a chest x-ray film for each patient. Additionally, a Great Ormond Street score was calculated from an echocardiogram as described by Celermajer and associates. ${ }^{5}$ This measure of the degree of right heart dilation is determined by the ratio of the combined area of the right atrium and atrialized portion of the RV divided by the area of the functional RV added to the area of the left heart chambers (in diastole). A ratio greater than 1 has previously been found to correlate with an overwhelming risk of mortality. ${ }^{3,6}$ The Great Ormond Street ratio has also been arbitrarily expressed as a severity score ranging from 1 to 4 . Grade 1 is characterized as a ratio less than 0.5 ; grade
2, 0.5 to 0.99 ; grade $3,1.0$ to 1.49 ; and grade 4 , equal to or greater than 1.5 .

\section{Surgical Technique}

Via a median sternotomy, standard aortic and bicaval cannulation is performed, and under moderate hypothermia $\left(28^{\circ} \mathrm{C}\right)$, the heart is arrested with cold blood cardioplegic solution. Through an oblique right atriotomy, the tricuspid valve is inspected and evaluated for possible repair. The degree of atrialized versus trabeculated (functional) RV is determined. Next the leaflet tissue is addressed. Most important, the ability to mobilize the anterior leaflet is evaluated because this leaflet must guard the majority of the neo-tricuspid valve orifice. The remnants of the small tethered septal and posterior leaflets also are assessed for the ability to integrate these structures into the repair. The right ventricular outflow tract (RVOT) is investigated. Any pulmonary stenosis or atresia must be addressed as part of a possible repair. If the ventricle is tripartite and the tricuspid valve tissue is adequate, repair of the valve is undertaken as described by Danielson and colleagues. ${ }^{7}$

If the tricuspid valve is not amenable to repair, or the functional portion of the RV is inadequate, or there is RVOT obstruction that cannot be reasonably corrected, then an RV exclusion (univentricular) strategy is undertaken. This is performed by patching the tricuspid valve with glutaraldehyde-fixed autologous pericardium sewn at the "anatomic" level of the tricuspid annulus. A 4-mm fenestration of the patch is then performed with a coronary punch. The coronary sinus is left on the right atrial side of the patch (in deference to the original description by Starnes and associates ${ }^{4}$ ). An unobstructed atrial septal opening is assured. A reduction right atrioplasty is carried out and, depending on the size of the atrialized portion, an RV plication is performed. Care is taken to avoid kinking of the right coronary artery. Next the RVOT is accessed. Early in the experience, when no fenestration of the patch was performed, small homografts were placed in the RVOT to assure an avenue for RV decompression. Since the introduction of the fenestration, this has not been needed. However, pulmonary valve insufficiency is treated with main pulmonary artery (PA) interruption. Finally, pulmonary blood flow is provided by a modified Blalock-Taussig shunt (3.5-4.0 mm) (Figures 1 and 2). The sternum is electively left open; the average time to closure was 2 days from the original operation.

\section{Results}

\section{Preoperative Imaging}

The mean cardiothoracic and Great Ormond Street ratios were $0.89 \pm 0.09$ and $1.07 \pm 0.55$, respectively. The mean Great Ormond Street severity score was 3. Neither ratio was a statistically significant predictor of mortality.

\section{Operative Course}

The median age at the initial palliative operation was 8 days (range 1-15 days). Three patients had tricuspid valve repair. One of these 3 patients was subsequently converted to RV exclusion 81 days after the initial valve repair. Because of extreme ventricular dysfunction, 1 patient underwent transplantation as the initial operation. Twelve of 16 patients underwent RV exclusion as their initial palliation. Ten of 


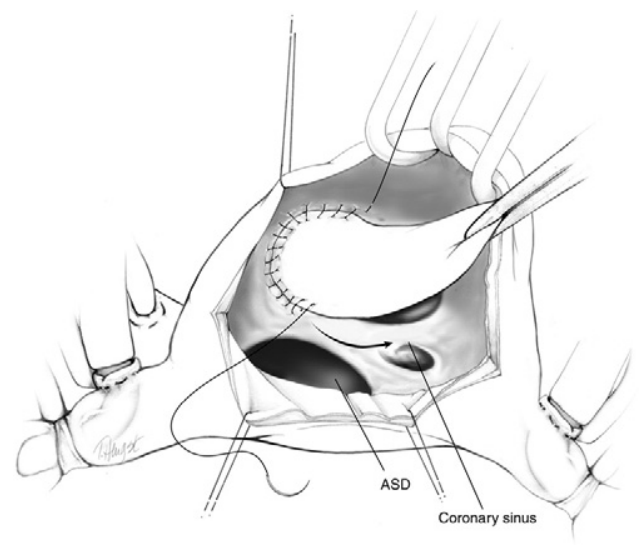

Figure 1. A glutaraldehyde-fixed autologous pericardial patch is sewn at the "anatomic" level of the tricuspid valve annulus. ASD, Atrial septal defect.

the exclusion procedures included a fenestration in the RV patch. There was no difference in bypass or aortic crossclamp time between those undergoing repair versus RV exclusion (bypass time $66 \pm 2$ minutes; aortic crossclamp time $26 \pm 6$ minutes). No heart block was observed perioperatively in any treatment group.

\section{RVOT Management}

Ten of the 13 patients who underwent RV exclusion had pulmonary atresia or severe pulmonary stenosis. Two patients early in the RV exclusion experience underwent placement of an RV-PA homograft. One patient had fenestration of the patch and the other did not; both patients died. Two of the 3 patients who underwent valve repairs required procedures to augment the RVOT: one had an autologous pericardial transannular patch and the other had placement of an RV-PA homograft. The patient who underwent the RVOT patch was subsequently converted to RV exclusion and the pulmonary outflow was interrupted. All patients who had homograft placement as a part of their operation had poor outcomes.

\section{Survival}

There were 5 hospital deaths at a median interval of 10.2 days postoperatively (range 0-20 days). There were no late deaths through an intermediate-term mean follow-up of 27 months (range 8-168 months). Among the 3 patients undergoing valve repair, 1 died, 1 had subsequent conversion to RV exclusion, and 1 is a long-term survivor. Only 1 of 3 patients with an unfenestrated tricuspid valve patch survived (33\%) whereas 8 of $10(80 \%)$ are alive after RV exclusion with fenestration. The small number of patients in the nonfenestrated cohort precludes a statistical verification of the difference between these groups (Figure 3, Table 1).

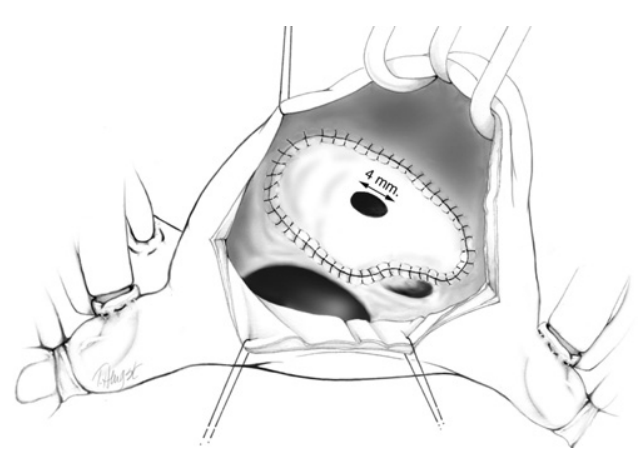

Figure 2. A 4-mm coronary punch is used to create a fenestration in the patch. The coronary sinus remains on the right atrial side of the patch.

All 9 survivors of RV exclusion have undergone a successful bidirectional Glenn shunt. Three have had successful Fontan completion. The remaining are Fontan candidates awaiting the appropriate time for their procedure. There have been no unexpected reoperations in this cohort.

\section{Discussion}

For a highly symptomatic neonate, the diagnosis of Ebstein anomaly formerly meant almost certain death. The anomaly itself presents with a range of anatomic features and clinical presentations. The valve may have minimal changes or it may be markedly displaced and adherent to an almost completely atrialized RV chamber. The surgical goal should be to palliate for optimum survival, and this may be accomplished with valve repair, RV exclusion, or transplantation. The anatomy will dictate the most appropriate palliation. Although Knott-Craig and colleagues ${ }^{8,9}$ have described tricuspid valve repair for the full spectrum of neonates and infants with excellent short- and mid-term results, theirs appears to be an isolated experience.

The RV exclusion procedure should have its biggest impact at the more severe end of the Ebstein spectrum where there is a diminutive true RV, highly laminated leaflet tissue, unguarded tricuspid valve orifice, and an obstructed RVOT. This is associated with marked dilation of the right side of the heart and subsequent impingement on the left ventricle. The RV exclusion technique decompresses the right side, allowing the left ventricle to function more effectively. Furthermore, in cases in which severe RVOT obstruction or atresia is present, RV exclusion eliminates the need for RVOT repair. This simplifies the initial palliation and precludes future procedures for conduit obstruction or insufficiency. The statement that a good singleventricle repair is better than a bad 2-ventricle repair may apply to such cases. ${ }^{10}$ Additionally, the potential benefit of a morphologically left ventricle providing systemic outflow may aid these palliated patients. 


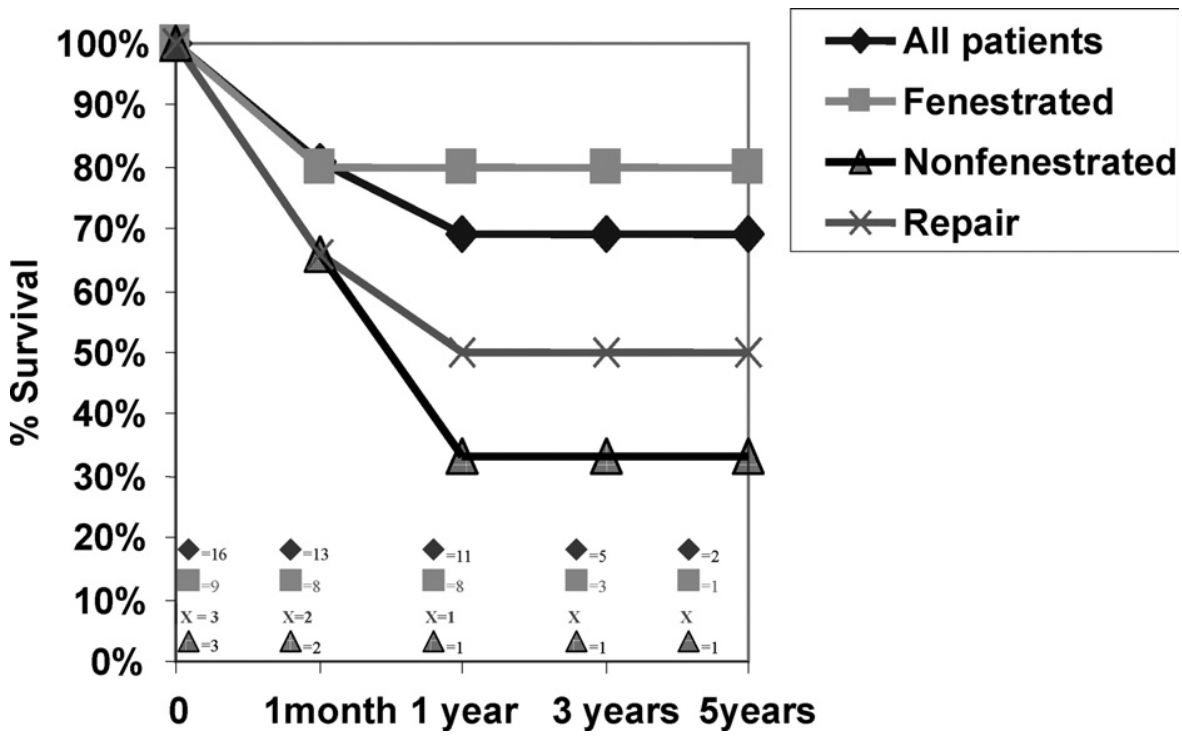

Figure 3. Survival among treatment groups.

The downside of the RV exclusion procedure is a commitment to the single-ventricle Fontan pathway, which currently requires at least two subsequent operations after initial palliation. Although few patients have undergone a successful valve repair after RV exclusion, there is precedence. ${ }^{8}$ There is also the potential for a one and a half ventricle repair after palliation by $\mathrm{RV}$ exclusion.

Another potential problem with single-ventricle repair in association with Ebstein anomaly is difficult access for catheter ablation of arrhythmias. However, late arrhythmias have not been a problem in our patients, and it may be that $\mathrm{RV}$ exclusion will decrease the incidence of atrial arrhythmias by eliminating important right atrial enlargement.

It is noteworthy that reports of valve repair for Ebstein anomaly describe residual tricuspid regurgitation in a majority of patients despite adequate repair. ${ }^{11,12}$ Tricuspid insufficiency combined with RVOT obstruction or pulmonary valve insufficiency may provide a substrate for a distention of the right atrium and subsequent late arrhythmias.

The RV exclusion technique has evolved over the 10 years since it was first described. Two elements have emerged with regard to optimal right-sided decompression. First, the coronary sinus has been retained on the right atrial side of the tricuspid valve patch. This is important because it leaves as

TABLE 1. Survival

\begin{tabular}{lccc}
\hline & \multicolumn{3}{c}{ Survival } \\
\cline { 2 - 4 } & One month (\%) & One year (\%) & Five years (\%) \\
\hline Fenestrated & 80 & 80 & 80 \\
Nonfenestrated & 66 & 33 & 33 \\
Valve repair & 66 & 50 & 50 \\
All patients & 81 & 69 & 89 \\
\hline
\end{tabular}

little blood draining into the excluded RV as possible. Our experience suggests that placement of the tricuspid valve patch so as to leave normal coronary sinus drainage can be accomplished without a major risk of injury to the conduction tissue. However, it is recognized that in general there may be an increased risk to the conduction tissue in Ebstein patients owing to the reported malpositioned atrioventricular node in some patients. ${ }^{13}$

The second and more significant modification to the RV exclusion technique has been the addition of a fenestration to the tricuspid valve patch. The fenestration was added after a patient with pulmonary atresia had persistent RV dilation. Since this experience we have advocated fenestration. This allows RV decompression, relieving impingement on the left ventricle with subsequent improvement in the systemic circulation. With the RV decompressed, an argument can be made to eliminate RV plication, which should decrease the potential risk of coronary artery distortion.

Transplantation should remain in the armamentarium when dealing with Ebstein anomaly. Particularly in the case of left-sided obstruction associated with Ebstein malformation, evaluation for transplantation should be seriously considered because such infants have a poor outcome with univentricular repair. Given the current shortage of donor hearts, these neonates may be considered for an ABOincompatible transplant to shorten the time on the waiting list. Mechanical support may also be required before a suitable donor becomes available.

In conclusion, we have sought to develop a systematic operative approach to neonates with symptomatic Ebstein anomaly. The tricuspid valve and RV should be evaluated for possible repair. In severe cases in which successful tricuspid valve repair appears uncertain, we advocate RV 
exclusion with fenestration and a systemic-to-pulmonary shunt. This surgical strategy has provided effective palliation for a group of patients that has historically had poor outcomes. For severe cases of Ebstein anomaly with associated left heart obstructive defects, transplantation should be considered.

\section{Limitations}

Although this is a relatively large series dealing with surgical intervention for neonates with Ebstein malformation presenting in a fulminate manner, the total number of patients is small and the power of the study is therefore affected. Additionally, the RV exclusion technique developed in a stepwise fashion, which did not allow for randomization to better elucidate the difference between patients with and without fenestration. Finally, we recognize that we may use the RV exclusion technique more readily because of our institutional experience and outcomes.

\section{References}

1. McElhinney DB, Salvin JW, Colan SD, Thiagarajan R, Crawford EC, Marcus EN, et al. Improving outcomes in fetuses and neonates with congenital displacement (Ebstein's malformation) or dysplasia of the tricuspid valve. Am J Cardiol. 2005;96:582-6.

2. Moura C, Guimaraes H, Areias JC, Moreira J. Ebstein's anomaly in neonates. Rev Port Cardiol. 2001;20:865-73.

3. Yetman AT, Freedom RM, McCrindle BW. Outcome in cyanotic neonates with Ebstein's anomaly. Am J Cardiol. 1998;81:749-54.

4. Starnes VA, Pitlick PT, Bernstein D, Griffin ML, Choy M, Shumway NE. Ebstein's anomaly appearing in the neonate: a new surgical approach. J Thorac Cardiovasc Surg. 1991;101:1082-7.

5. Celermajer DS, Cullen S, Sullivan ID, Spiegelhalter DJ, Wyse RK, Deanfield JE. Outcome in neonates with Ebstein's anomaly. J Am Coll Cardiol. 1992;19:1041-6.

6. Celermajer DS, Bull C, Till JA, Cullen S, Vassillikos VP, Sullivan ID, et al. Ebstein's anomaly: presentation and outcome from fetus to adult. J Am Coll Cardiol. 1994;23:170-6.

7. Danielson GK, Mair DD, Warnes CA, Oliver WC. Operative treatment of Ebstein's anomaly. J Thorac Cardiovasc Surg. 1992;104:1195-202.

8. Knott-Craig CJ, Overholt ED, Ward KE, Razook JD. Neonatal repair of Ebstein's anomaly: indications, surgical technique, and mediumterm follow-up. Ann Thorac Surg. 2000;69:1505-10.

9. Knott-Craig CJ, Overholt ED, Ward KE, Ringewald JM, Baker SS, Razook JD. Repair of Ebstein's anomaly in the symptomatic neonate: an evolution of technique with 7-year follow-up. Ann Thorac Surg. 2002;73:1786-92; discussion 1792-3.

10. Delius RE, Rademecker MA, de Leval MR, Elliott MJ, Stark J. Is a high-risk biventricular repair always preferable to conversion to a single ventricle repair? J Thorac Cardiovasc Surg. 1996;112:1561-8; discussion 1568-9.

11. Chen JM, Mosca RS, Altman K, Printz BF, Targoff K, Mazzeo PA, Quaegebeur JM (2004). Early and medium-term results for repair of Ebstein anomaly. J Thorac Cardiovasc Surg. 2004;127:990-9.

12. Chauvaud S. Ebstein's malformation: surgical treatment and results. Thorac Cardiovasc Surg. 2000;48:220-3.

13. Ho SY, Goltz D, McCarthy K, Cook AC, Connell MG, Smith A, et al. The atrioventricular junctions in Ebstein malformation. Heart. 2000; 83:444-9.

\section{Discussion}

Dr Christopher J. Knott-Craig (Oklahoma City, Okla). I rise to congratulate you on the first major presentation on patients with neonatal Ebstein anomaly and on the continued results that you have shared with us. In your presentation you review a 14-year experience with 16 patients, most of whom underwent RV exclusion and have excellent outcomes based on historical norms.

We also have a good experience with neonatal Ebstein patients, having had the opportunity to operate on 22 of these patients over 12 years; we have taken a different approach in that we have attempted a 2-ventricle repair in all of them with a greater than $70 \%$ survival.

Clearly, there is room to do an RV exclusion operation and there is room to do a 2-ventricle repair. The dilemma that we face as surgeons is trying to stratify which patients would do better with one operation versus the other. Can you help us make a decision based on your experience? Do you have any insights that you could share with us based on your most recent experience in this regard?

Dr Reemtsen. I think the million-dollar question is, when should this be done? We think of the RV exclusion as more of a tool to deal with Ebstein anomaly than as an answer. If the valve tissue looks good and we think we can approach a repair and there is a tripartite ventricle with an open RVOT, then we absolutely will attempt to repair the malformation. If we are not able to do, by echocardiogram, an adequate repair, we would do an RV exclusion at that point.

I think the more difficult group is the one in which there is failure at delamination, there is really no identifiable leaflet tissue, and there is an obstructed RVOT. I do not think, at least in our hands, that we can get an adequate repair as well as we have now. We have to open up the RVOT with a small homograft, and we all know the implications of that.

Trying to see whether there is a usable ventricle is our main goal, as well as valve tissue that will give us a repair that would be less than mild, mild or less, on an echocardiogram.

Dr Knott-Craig. One may argue that if you do a very aggressive tricuspid valve annuloplasty and have a regurgitant valve at the end, you may, at least physiologically, have pretty much the same results as if you sew a patch of tissue to the tricuspid valve annulus and fenestrate it. I think ultimately the two end points may not be very dissimilar, at least in a certain group of patients.

Could you tell us a little bit about the patient in whom a heart transplant was performed? How did you decide on transplantation for that patient in contradistinction to the other patients?

Dr Reemtsen. This patient was the only one who had really severe left-sided malformations, had hypoplasia of the mitral valve relatively, and had moderate valve regurgitation in association with a coarctation. We believed that surgery would be high risk in this patient, who had a univentricular heart with the only valve being the mitral valve, so we listed that patient as soon as we could.

Dr Knott-Craig. My final question relates to your entire cohort of patients. Is it possible that some of these patients might not need an operation in the early postpartum period? How did you differentiate between these and the really sick neonates? How did you stabilized them in the preoperative period?

Dr Reemtsen. We didn't stabilize them. Essentially, the patients that we operated on had not responded to medical therapy. I know that there is a movement now to incorporate nitric oxide and try to get these patients out of the neonatal period, but we do not have a lot of experience with that approach. I think if that is able 